\title{
Some minor female reproductive system disorders: findings in the Oxford-Family Planning Association contraceptive study
}

\author{
Martin Vessey, David Yeates
}

\begin{abstract}
Background The Oxford-Family Planning Association (Oxford-FPA) contraceptive study has provided information on many serious diseases of the female reproductive tract. No information has been published about a number of common minor conditions. This report fills the gap with regard to uterine polyp, cervicitis, cervical erosion, and vaginitis and vulvitis.
\end{abstract}

Methods The Oxford-FPA study includes 17032 married women recruited at ages 25-39 years between 1968 and 1974 from clinics in England and Scotland. These women were followed up until mid-1994. Information collected during follow-up included details of contraceptive use, cervical smears taken at the clinic, pregnancies and hospital referrals.

Results Oral contraceptive (OC) use was associated with a reduction in first hospital referral for uterine polyp and for vaginitis and vulvitis, which became more marked with increasing duration of use. There was a slightly increased rate of hospital referral for cervicitis in OC users. Referral for cervical erosion was markedly increased in current and recent OC users (rate ratio 2.1, 95\% confidence interval 1.8-2.4). This increase in risk steadily declined after OC use was discontinued. First hospital referral for both uterine polyp and cervical erosion showed a highly significant negative association with numbers of cigarettes smoked per day. The explanation for these observations is unknown.

Conclusions It should be remembered that the OCs studied were mainly those used in the 1970s and 1980s and mostly contained $50 \mu \mathrm{g}$ estrogen. On balance, the overall effect of $\mathrm{OC}$ use on the conditions considered was neutral or beneficial. The apparent protective effect of cigarette smoking against uterine polyp and cervical erosion, even if valid, counts as nothing against the overwhelming adverse effects of smoking on health.

Keywords cervical erosion, cervicitis, oral contraceptives, uterine polyp, vaginitis/vulvitis

J Fam Plann Reprod Health Care 2009; 35(2): 105-110 (Accepted 11 February 2009)

\section{Introduction}

The Oxford-Family Planning Association (Oxford-FPA) contraceptive study started in 1968 with the primary aim of evaluating the benefits and risks of different birth control methods. ${ }^{1}$ Several detailed papers have been published reporting the study findings on a range of disorders of the female reproductive system including tumours of the uterine cervix ${ }^{2,3}$ and body, ${ }^{3}$ ovarian tumours, 3,4 infertility, 5 pelvic inflammatory disease, ${ }^{6}$ uterine fibroids, ${ }^{7}$ endometriosis, ${ }^{8}$ menstrual disorders ${ }^{9}$ and uterine prolapse. ${ }^{10}$ There remain, however, a number of frequently occurring, but relatively minor, conditions of the reproductive tract that have not been the subject of a report. These include uterine polyp, cervicitis, cervical erosion, and vaginitis and vulvitis. We considered it would be of interest to examine the study data for these conditions and we present our findings here, paying special attention to the importance of the role of oral contraceptive (OC) use.

\section{Methods}

\section{Study design and study subjects}

A detailed description of the methods used in the OxfordFPA study has been given elsewhere. ${ }^{1}$ In brief, 17032 women were recruited at 17 large family planning clinics in England and Scotland between 1968 and 1974. When recruited, each woman had to be (a) aged between 25 and 39 years, (b) married, (c) white and British (d) willing to

Unit of Health Care Epidemiology, University of Oxford, Oxford, UK

Martin Vessey, FRcOG, FRS, Emeritus Professor of Public Health David Yeates, PhD, Computer Scientist

Correspondence to: Professor Martin Vessey, Unit of Health Care Epidemiology, Rosemary Rue Building, Old Road Campus, Headington, Oxford OX3 7LF, UK.

E-mail: martin.vessey@dphpc.ox.ac.uk

\section{Key message points}

- In the Oxford-FPA study, oral contraceptive (OC) use was associated with a reduction in the risk of first hospital referral for uterine polyp and for vaginitis and vulvitis, which became more marked with increased duration of use.

- Cervicitis showed a modest positive association with OC use, which was independent of duration of use.

- The risk of hospital referral for cervical erosion was more than doubled in current and recent OC users. This increase in risk steadily declined after OCs were discontinued.

- Hospital referral rates for both uterine polyp and cervical erosion diminished with increasing numbers of cigarettes smoked. Even if valid and causal, these beneficial effects would be trivial if compared with the devastating effects of smoking on health.

co-operate and (e) either a current user of OCs of at least 5 months standing or a current user of a diaphragm or an intrauterine device (IUD) of at least 5 months standing without previous exposure to OCs. Among other items, each woman was asked at entry about her age, childbearing history, contraceptive history, height and weight, social class, smoking behaviour and past medical history.

During follow-up, each woman was questioned at return visits to the clinic and certain items of information were noted on a special form. These included details of pregnancies and their outcome, changes in contraceptive practices and reasons for the changes, the results of cervical smears taken at the clinic, and particulars of any referrals to hospital as an outpatient or inpatient. Clinic staff were requested to take cervical smears with the same frequency from all women irrespective of the contraceptive method they were using as this represented good clinical practice. The actual frequency was not laid down although the majority of clinics aimed at taking smears every 2 years. Diagnoses on discharge from an inpatient hospital spell 
were confirmed by obtaining copies of discharge letters, summaries and pathology reports. Conversely, diagnoses following an outpatient consultation were reported by the women themselves. The Eighth Revision of the International Classification of Disease (ICD) was used for coding diagnoses and one of the authors (MV) was responsible for carrying out all disease coding throughout the course of the study. The ICD codes relevant to the present analyses are as follows: uterine polyp (219.0), cervicitis (620.0), cervical erosion (621.3) and vaginitis and vulvitis (622.1).

Women who stopped attending the clinic were followed up annually by post, telephone or home visit. The data sought were the same as those recorded at clinic visits save that no information was collected about cervical smears. This was because we considered that such information would be too inaccurate to be of value. The work in each clinic was co-ordinated by a part-time research assistant and follow-up was maintained until the women in the study reached the age of 45 years with an annual loss of contact or loss of co-operation rate of only around $0.4 \%$. On reaching the age of 45 years, each woman was allocated to one of three OC use groups: (a) OCs never used, (b) OCs used for a total of 8 years or more and (c) other durations of OC use. Only women in the first two groups were subsequently followed annually in the way already described. Accordingly, women in group (c) have been omitted from the present analysis from the age of 45 years onwards. From mid-1994, individual follow-up of all the women was discontinued although information about deaths and cancer registrations, using the National Health Service central registries, is still being collected. . $^{311}$

Unfortunately, the Eighth Revision of the ICD includes all uterine polyps (cervical and endometrial) within one rubric (219.0). In addition, the detailed written records of the Oxford-FPA study have now been securely archived, which makes access difficult. Nonetheless, we drew a random sample of 100 women with a diagnosis coded 219.0 and recovered the full records from the archive. We found that only about $20 \%$ of the sample had an endometrial polyp, so it can be assumed that our data relating to uterine polyps essentially concern lesions of the cervix.

\section{Analytical methods}

The analyses are based on the computation of woman-years of observation terminated by (a) first referral to hospital for the condition under consideration or (b) the occurrence of hysterectomy (only for the analyses concerning uterine polyp, cervicitis or cervical erosion) or (c) release from follow-up (emigration, loss of co-operation, death, shortterm OC users reaching the age of 45 years) or (d) loss to follow-up or (e) the end of the study (July 1994 for the present analyses).

Women with a history of the condition under consideration at entry to the study were omitted from the analyses concerning that condition. Only the first occurrence of the relevant condition was considered in each analysis, so affected women appear only once in any given table.

Indirectly standardised first event rates were calculated by the method described by Vessey et al. ${ }^{1}$ The calculation of rate ratios (RRs), tests of significance and confidence intervals (CIs) was based on methods described by Breslow and Day. ${ }^{12}$ Details of the confounding variables taken into account in each analysis are given in the table footnotes.

We recognised that the frequency with which cervical smears were taken might influence the rate of diagnosis of the cervical disorders considered in this report. Although this variable could not be included in the main analyses (since only data on clinic smears were recorded), we nonetheless examined the available data to see if any important patterns emerged. For this purpose, we identified three cohorts of women, namely those who entered the study using OCs, a diaphragm or an IUD. We then censored each cohort by whichever of the following events occurred first: (a) a change of contraceptive method or (b) discontinuation of clinic attendance. Smear frequencies were then estimated within each cohort. This approach enabled us to make an unbiased assessment of clinic cervical screening practice in relation to contraceptive method and other variables.

\section{Results}

\section{Numbers of subjects and influence of age}

The numbers of women referred to hospital with each of the diagnoses under consideration, together with incidence rates by age, are shown in Table 1. Uterine polyp and cervical erosion were the two most frequent diagnoses with over 1000 women in each of these two categories. The rates for uterine polyp rose markedly with age although there was some falling off in the highest age group. By contrast, the rates for cervical erosion fell extremely rapidly with increasing age; those for vaginitis and vulvitis showed a similar but much lesser trend. Cervicitis rates were in the form of an inverted $U$ with a peak at ages 40-44 years.

\section{Inter-relationships between diagnoses}

As would be expected, some women had more than one of the four diagnoses under study and thus appear in more than one set of analyses. The proportions of women in each of the four groups with the index diagnosis alone were: uterine polyp, $78 \%$; cervicitis, $76 \%$; cervical erosion, $77 \%$; vaginitis and vulvitis, $74 \%$. We considered that there was sufficient independence between the diagnostic groups to justify including all the women with the index diagnosis in each set of analyses and that restriction of the analyses to women with only one diagnosis might introduce selection bias.

\section{Confounding variables}

The next set of analyses was aimed at examining the effects of variables, in addition to age, which might confound the comparisons of $\mathrm{OC}$ use. The age-adjusted findings are summarised in Table 2, which reveals some interesting

Table 1 First hospitalisation rates per 10000 woman-years by age for the different disorders. Numbers of women affected are given in parentheses

\begin{tabular}{|c|c|c|c|c|}
\hline Age (years) & $\begin{array}{l}\text { Uterine polyp } \\
(n=1011)\end{array}$ & $\begin{array}{l}\text { Cervicitis } \\
(n=601)\end{array}$ & $\begin{array}{l}\text { Cervical erosion } \\
(n=1010)\end{array}$ & $\begin{array}{l}\text { Vaginitis/vulvitis } \\
(n=373)\end{array}$ \\
\hline $25-34$ & $11 \quad(79)$ & $11 \quad(72)$ & 67 (442) & $19(130)$ \\
\hline $35-39$ & 27 (187) & $18(116)$ & $49(300)$ & 14 (92) \\
\hline $40-44$ & 40 (278) & $33(213)$ & $30(190)$ & 11 (75) \\
\hline $45-49$ & $63(236)$ & $32(112)$ & 18 (61) & 10 (38) \\
\hline $50-54$ & 74 (164) & 32 (68) & 7 (15) & 10 (26) \\
\hline $55+$ & $59 \quad(67)$ & 18 (20) & 2 (2) & 9 (12) \\
\hline
\end{tabular}


Table 2 Summary of statistical significance of associations between first hospital referral rates for the different disorders and various possible risk factors. The rates on which the table is based were standardised for age (see Table 1)

\begin{tabular}{|c|c|c|c|c|}
\hline $\begin{array}{l}\text { Possible risk } \\
\text { factors }\end{array}$ & $\begin{array}{l}\text { Uterine polyp (p) } \\
(n=1011)\end{array}$ & $\begin{array}{l}\text { Cervicitis }(p) \\
(n=601)\end{array}$ & $\begin{array}{l}\text { Cervical erosion }(p) \\
(n=1010)\end{array}$ & $\begin{array}{l}\text { Vaginitis/vulvitis (p) } \\
(n=373)\end{array}$ \\
\hline Parity & 0.100 & 0.001 (pos) & 0.001 (pos) & 0.111 \\
\hline Social class & $<0.001$ (pos) & 0.349 & 0.904 & 0.130 \\
\hline Smoking & $<0.001$ (neg) & 0.235 & 0.001 (neg) & 0.075 \\
\hline Height & 0.640 & 0.016 (pos) & 0.623 & 0.183 \\
\hline Weight & 0.291 & 0.240 & 0.510 & 0.288 \\
\hline Body mass index & 0.486 & 0.651 & 0.297 & 0.025 (neg) \\
\hline
\end{tabular}

Significance tests are based on Chi-square for trend on 1 degree of freedom (DF). neg, negative; pos, positive.

Groupings used in trend analyses: parity (number of term births): 0, 1-2, 3 or more; social class at entry (Registrar General's Classification): I-II (“upper"), III (“middle"), IV-VI (“lower"); smoking at entry: never smoked, ex-smoker, 1-14 cigarettes/day, 15 or more cigarettes/day; height at entry (inches): up to $60,61-62,63-64,65-66,67$ or more; weight at entry (pounds): up to 112, 113-126, 127-140, 141-154, 155 or more; body mass index at entry $\left(\mathrm{kg} / \mathrm{m}^{2}\right)$ : less than 20, 20-21.9, 22-23.9, 24-25.9, 26-27.9, 28 or more: calendar period (years); 1968-1974, 1975-1979, 1980-1984, 1985-1989, 1990-1994.

Table 3 First hospitalisations for the various diagnostic groups in relation to total duration of oral contraceptive use. The data given are numbers of cases $(n)$ and rate ratios with $95 \%$ confidence intervals

\begin{tabular}{|c|c|c|c|c|c|c|c|c|c|c|c|c|}
\hline \multirow{2}{*}{$\begin{array}{l}\text { Total duration } \\
\text { OC use (months) }\end{array}$} & \multicolumn{3}{|c|}{ Uterine polyp } & \multicolumn{3}{|c|}{ Cervicitis } & \multicolumn{3}{|c|}{ Cervical erosion } & \multicolumn{3}{|c|}{ Vaginitis/vulvitis } \\
\hline & $n$ & RR & $\mathrm{Cl}$ & $n$ & RR & $\mathrm{Cl}$ & $n$ & RR & $\mathrm{Cl}$ & $n$ & RR & $\mathrm{Cl}$ \\
\hline Non-user & 590 & 1 & - & 240 & 1 & - & 255 & 1 & - & 163 & 1 & - \\
\hline$\leq 24$ & 60 & 1.0 & $0.7-1.2$ & 44 & 1.4 & $1.0-1.9$ & 98 & 1.4 & $1.1-1.8$ & 41 & 1.1 & $0.8-1.6$ \\
\hline $25-48$ & 65 & 0.8 & $0.6-1.0$ & 44 & 1.0 & $0.7-1.4$ & 177 & 1.8 & $1.4-2.1$ & 49 & 0.9 & $0.6-1.3$ \\
\hline $49-72$ & 76 & 0.8 & $0.6-1.0$ & 61 & 1.2 & $0.9-1.6$ & 180 & 1.8 & $1.5-2.2$ & 42 & 0.8 & $0.5-1.1$ \\
\hline $73-96$ & 58 & 0.7 & $0.5-0.9$ & 49 & 1.1 & $0.8-1.6$ & 136 & 1.9 & $1.5-2.4$ & 25 & 0.6 & $0.4-1.0$ \\
\hline $97-120$ & 81 & 0.6 & $0.5-0.8$ & 70 & 1.3 & $1.0-1.7$ & 86 & 1.6 & $1.3-2.1$ & 22 & 0.6 & $0.4-0.9$ \\
\hline $121+$ & 81 & 0.4 & $0.3-0.5$ & 93 & 1.2 & $0.9-1.6$ & & 1.6 & $1.2-2.0$ & 31 & 0.7 & $0.5-1.0$ \\
\hline $\begin{array}{l}\text { Chi-square trend test } \\
\text { (1 DF) }\end{array}$ & \multicolumn{3}{|c|}{$p<0.001$} & \multicolumn{3}{|c|}{$p=0.044$} & \multicolumn{3}{|c|}{$p<0.001$} & \multicolumn{3}{|c|}{$p=0.001$} \\
\hline
\end{tabular}

Rate ratios are adjusted for the following factors: uterine polyp: age, social class, smoking; cervicitis: age, parity, height; cervical erosion: age, parity, smoking; vaginitis/vulvitis: age, body mass index. For details of groupings see footnote to Table 1.

$\mathrm{Cl}$, confidence interval; DF, degrees of freedom; OC, oral contraceptive; RR, rate ratio.

associations. Increasing parity was strongly positively associated with both cervicitis and cervical erosion, as was social class with uterine polyp. The strong negative associations between smoking and both uterine polyp and cervical erosion were unexpected. Measures of body size seemed to be of little importance overall although there were two significant associations (cervicitis positively with height and vaginitis and vulvitis negatively with body mass index). We considered it essential to examine the data for diagnostic trends with time and found significant negative associations for cervical erosion and for vaginitis and vulvitis. The negative trend for cervical erosion was particularly profound with the age-adjusted rate in 1990-1994 being only one third of that in 1968-1974.

\section{Oral contraceptive use}

In addition to age, we decided to include the variables shown in Table 2, which reached statistical significance as potential confounders in our analyses of OC use. In the first set of analyses, however, we omitted calendar period. We then re-ran the analyses including this variable (where relevant) as well as the others to see if any important changes occurred in the RR estimates.

The findings in relation to total duration of OC use are given in Table 3. The RRs for uterine polyp showed a profound and near linear decline with increasing duration of OC use. A similar, but less striking, decline was also apparent for vaginitis and vulvitis. Conversely, first hospital referral rates for cervical erosion were markedly increased in OC users but this increase was more or less the same for all durations of OC use. The RRs for cervicitis were also slightly increased in OC users but duration of use had little, if any, effect.
When an adjustment for the effect of calendar period was added in to the analyses (for the two conditions affected by this variable - see Table 2) there was a modest general increase in the RRs for cervical erosion. There was also a slight increase in the RRs for vaginitis and vulvitis although the downward trend with duration of $\mathrm{OC}$ use remained significant $(p=0.014)$.

Table 4 corresponds to Table 3 but is concerned with the effect of the interval since OCs were last used. The data for uterine polyp indicate a significant reduction of risk at all intervals since last $\mathrm{OC}$ use although there is some tendency for the effect to wear off with the passage of time. The only disorder strongly related to interval since last OC use was cervical erosion. Thus the RR for first hospitalisation for this condition fell from 2.1 (95\% CI 1.8-2.4) in women who last used OCs within 12 months (including current users) to 1.0 (95\% CI 0.7-1.3) in those who had last used OCs more than 8 years before. This trend was somewhat reduced when calendar period was considered in the analysis as well as the other variables but remained highly significant.

We also examined the frequency with which clinic smears were taken within the three contraceptive methods at entry cohorts described in the analytical methods section above. The rates per 100 woman-years of follow-up were 55 for OC users, 52 for diaphragm users and 59 for IUD users. Smear frequency showed no important relationship to duration of use in any of the cohorts. Clinic staff had clearly followed the practice that we had suggested.

\section{Cigarette smoking}

While Table 2 gives overall information about the influence of variables other than OC use on the various disorders, we considered that the unexpected effect of smoking on uterine 
Table 4 First hospitalisations for the various diagnostic groups in relation to interval since last oral contraceptive use. The data given are numbers of cases $(n)$ and rate ratios with $95 \%$ confidence intervals

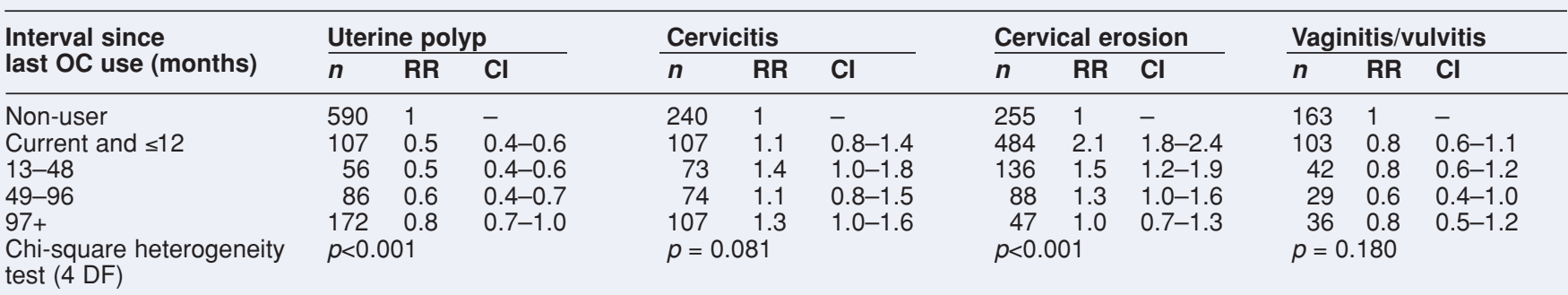

Rate ratios are adjusted for the following factors: uterine polyp: age, social class smoking; cervicitis: age, parity, height; cervical erosion: age, parity, smoking; vaginitis/vulvitis: age, body mass index. For details of groupings see footnote to Table 1 .

$\mathrm{Cl}$, confidence interval; $\mathrm{DF}$, degrees of freedom; OC, oral contraceptive; RR, rate ratio.

polyp and cervical erosion was of sufficient interest to justify more detailed analysis, including adjustment for the effect of OC use. The findings are summarised in Table 5.

The strong negative association between hospitalisation for uterine polyp and cigarette smoking persists unabated after adjustment for potential confounding factors. The similar negative association between smoking and cervical erosion is actually slightly increased in size and significance after allowing for potential confounding factors. Adding in the influence of calendar period to the analysis had a minimal effect on these results.

We also examined the frequency with which clinic smears were taken within the different smoking groups. As anticipated, there was no relationship between cigarette smoking and smear frequency. Thus the overall frequencies per 100 woman-years of follow-up were 57,57 and 59 for those who never smoked, ex-smokers and current smokers, respectively.

\section{Discussion}

\section{Limitations of the data}

The data collected in the Oxford-FPA study are known to be reliable and of good quality and have been subjected to a wide range of analyses. ${ }^{13}$ Nonetheless, the results presented here have a number of important limitations. First, the disorders considered are all relatively minor ones and it is possible that a woman might have been more ready to report a problem to her general practitioner (GP) if she believed it had been caused by her contraceptive method. Similarly, a GP might have been influenced by knowledge of a woman's contraceptive method in making a decision about whether or not to refer her to hospital. Our analyses are, of course, limited to episodes of disease reported after hospital assessment and may be subject to the influence of such selection bias. Second, women who were seen only as outpatients self-reported their diagnoses which, no doubt, were sometimes inaccurate although this should not in itself have led to bias. Third, the diagnoses considered were not mutually exclusive although the degree of overlap was small enough in our view to justify separate analysis of each diagnosis. Fourth, all the disorders (save perhaps for uterine polyp) are poorly defined allowing scope for misdiagnosis and diagnostic bias. In particular, it should be noted that we do not have details of the organisms involved in cases of cervicitis or vaginitis and vulvitis save for the gonococcus (infections with this organism have a separate ICD rubric). It is clear that gonococcal infections were unimportant in our study since only three women are known to have suffered from gonorrhoea during follow-up. Fifth, it is possible that some of the diagnoses considered in our analysis were made at the time a cervical smear was taken. We can provide reassurance that the frequency with which smears were taken at the clinic showed no important relationship to contraceptive method (or to smoking habit) but we have no information about the pattern of cervical screening once women stopped attending the clinic. Nonetheless, we consider that important bias from this source is unlikely since national screening policy has at no time taken a woman's contraceptive method into account. Finally, the women who make up the non-user group in the various OC comparisons include those using a diaphragm, an IUD, condoms, male or female sterilisation, spermicides, the rhythm method and coitus interruptus as well as no method at all. It is possible that some of these methods may have had an influence, positive or negative, on the risk of some or all of the conditions we have considered. It should be remembered, however, that all these methods would also have been used to a varying extent by the ex-users of OCs.

In addition to the above limitations, our data on uterine polyp, while mostly referring to women with cervical disease, also include a small proportion of women (around $20 \%$ ) with endometrial polyp. It seems likely that different factors might influence the risk of polyps of these two sites. Nonetheless, it seems reasonable to consider our findings as essentially relating to cervical polyp.

Table 5 Relationship between cigarette smoking and first hospitalisation for (a) uterine polyp and (b) cervical erosion. The data given are numbers of cases $(n)$ and rate ratios with $95 \%$ confidence intervals

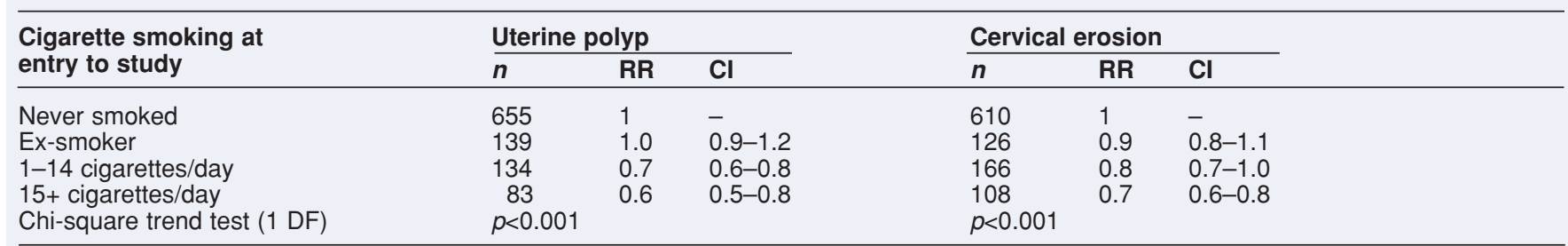

Rate ratios adjusted for the following factors: uterine polyp: age, social class, total duration OC use; cervical erosion: age, parity, total duration OC use. For OC use groupings see Table 3.

$\mathrm{Cl}$, confidence interval; DF, degrees of freedom; OC, oral contraceptive; RR, rate ratio. 


\section{Uterine polyp}

First hospital referral for uterine polyp was strongly related to several variables in the present study. First, it was much more frequent in women of higher social class than in other women. This might be related to greater use of health services by such women, but against that explanation is the fact that the other three conditions under investigation were unrelated to social class. In addition, first referral for uterine polyp was substantially less common in cigarette smokers than in non-smokers or ex-smokers. Turning to the effect of OC use, there was a strong linear negative relationship with duration of use. In addition, there was some evidence that the effect of OC use wore off with the passage of time since OC use was discontinued.

The smoking and OC use associations are difficult to explain. It might, perhaps, be argued that since both OC use and smoking reduce the risk of endometrial cancer, ${ }^{14}$ a similar effect might apply to endometrial polyps. Against this argument, however, is the fact that we have found no significant relationship between endometrial hyperplasia (99 cases) and either OC use or smoking in the Oxford-FPA study (unpublished data). Again, since the great majority of polyps in our study were cervical in location it seems unlikely that explanations based on the behaviour of endometrial polyps, even if valid, could explain associations of the strength we have found.

Our examination of the published literature was generally unhelpful. Three recent major reviews of OC effects made no reference at all to uterine polyps. ${ }^{15-17}$ Likewise, we were unable to find other reports that considered uterine polyps in relation to smoking and OC use. Nonetheless, it is gratifying that our findings in relation to OC use are favourable; any possible beneficial effect of smoking would, of course, be far outweighed by the overwhelming harmful effects of that habit.

\section{Cervicitis}

While our observations on uterine polyp are puzzling, those relating to cervicitis are much less so. The positive association with parity was expected, but that with height was not. This latter finding might, perhaps, be attributed to the play of chance. The only other point of note is that first hospital referral for cervicitis was slightly more frequent in OC users than in non-users. This modest association was, however, very non-specific. Thus the risk was unrelated both to duration of OC use and to interval since last use; it therefore seems unlikely to represent a true effect.

Of the three recent reviews referred to above, only one made reference to cervicitis with the statement that "prevention of cervical infection is not a non-contraceptive benefit from OC use". ${ }^{17}$ Our findings are clearly in line with that statement. A number of other authors have reported findings suggesting some modest positive relationship between OC use and cervicitis although there is wide variation in the definition of the disorder from study to study while our findings are difficult to interpret because of the lack of microbiological information. ${ }^{18-21}$

\section{Cervical erosion}

Our observations with respect to cervical erosion (or cervical ectropion) are of particular interest. First, the positive association with increasing parity was expected. Second, we became aware during the course of our study that cervical erosion was increasingly regarded by doctors as a variation of normal rather than as a pathological condition. This change of attitude would be expected to result in a strong negative association between first referral rates and calendar year of the type that we have observed. Third, the apparent reduction in the likelihood of hospital referral with increasing levels of cigarette smoking was unexpected but closely similar to the pattern observed with uterine polyp. Finally, first referral rates were much higher in OC users than in non-users. There was, however, no indication that duration of OC use was of importance. Conversely, the relationship with interval since last use was impressive. First referral rates were more than twice as high in current and recent users as in non-users, but this difference had entirely disappeared 97 or more months after OC use had ceased. This observation is clearly consistent with a causal relationship between OC use and cervical erosion.

Of the three recent reviews, two refer to a positive association between OC use and cervical erosion. ${ }^{15,17}$ One of the first and perhaps the most convincing of the individual studies showing such an association was reported by one of the present authors (MV) and colleagues in 1978.22 Other studies reaching similar conclusions include Harrison et al.,23 Critchlow et al..$^{20}$ and Ozbay and Yardim. ${ }^{24}$ We have been unable to find another study considering the relationship between cigarette smoking and cervical erosion. Once again, if our observation is valid, it is totally unimportant when considered in relation to the harm associated with smoking.

\section{Vaginitis and vulvitis}

Turning now to vaginitis and vulvitis, our findings are once again limited by the absence of any microbiological information. The modest negative association with body mass index may well be ascribed to chance but it is certainly true that this diagnosis was made increasingly less frequently as the study progressed. First referral rates fell with increasing duration of $\mathrm{OC}$ use but there was no association with interval since last use.

Examination of the three major reviews yielded scant information about vaginitis and vulvitis, although one stated that there was no causal link between OC use and candidiasis. ${ }^{15}$ Individual studies, however, have provided inconsistent results, some suggesting a positive association $^{25,26}$ and some not. ${ }^{27,28}$ In the study referred to earlier, which included one of us (MV) as an author, no significant association was found between vaginal pathogens and OC use. 22,29 Many other studies have reported on the relationship between bacterial vaginosis and OCs: they have tended to find little or no effect, ${ }^{30,31}$ or even a protective effect. ${ }^{32,33}$ Our findings are thus not unduly out of line with those of others.

\section{Conclusions}

Although the conditions considered in the present report are not life threatening, they can nonetheless cause considerable ill health and lead to surgical intervention. OC use showed a modest positive association with cervicitis, which, in our opinion, is unlikely to be causal. Conversely, the positive association with cervical erosion was strong, with the risk diminishing once OC use stopped. While cervical erosion may be regarded as a variation of normal, it has been associated with an increase in vaginal discharge and perhaps with nocturia and frequency of micturition and is therefore undesirable. ${ }^{22}$ Furthermore, in the past at least, cervical erosion has often been treated invasively.

The other two conditions considered, namely uterine polyp, and vaginitis and vulvitis, both showed a significant negative association with duration of OC use in our study. Our overall conclusion would therefore be that, on balance, the effect of OC use on hospital referral for the conditions we have considered is neutral or beneficial, which is reassuring. It should, of course, be remembered that the OC preparations used by the women in our study were mainly 
those available in the 1970s and 1980s and were mostly those containing $50 \mu \mathrm{g}$ estrogen. Different findings might be obtained with the preparations in widespread use today.

The apparent protective effect of cigarette smoking on uterine polyp and cervical erosion was unexpected and remains unexplained. We would, however, stress once again that these apparent protective effects, even if true, weigh as nothing in comparison with the harm done by smoking.

\section{Acknowledgements}

The authors are deeply grateful for the support received from the Medical Research Council. They also acknowledge with sincere gratitude the loyal support received from many research assistants, doctors, nurses and other staff over the years. Finally, they thank the women who have taken part in the Oxford-FPA study without whom none of this work could have been done.

Statements on funding and competing interests

Funding This study was funded throughout by the Medical Research Council.

Competing interests None identified.

\section{References}

1 Vessey MP, Doll R, Peto R, Johnson B, Wiggins P. A long-term follow-up study of women using different methods of contraception - an interim report. J Biosoc Sci 1976; 8: 373-425.

2 Zondervan KT, Carpenter LM, Painter R, Vessey MP. Oral contraceptives and cervical cancer - further findings from the Oxford-Family Planning Association contraceptive study. $\mathrm{Br} \mathrm{J}$ Cancer 1996; 73: 1291-1297.

3 Vessey M, Painter R. Oral contraceptive use and cancer. Findings in a large cohort study. $\mathrm{Br} J$ Cancer 2006; 95: 385-389.

4 Vessey MP, Painter R. Endometrial and ovarian cancer and oral contraceptives - findings in a large cohort study. $\mathrm{Br} J$ Cancer 1995; 71: 1340-1342.

5 Vessey MP, Smith MA, Yeates D. Return of fertility after discontinuation of oral contraceptives: influence of age and parity. Br J Fam Plann 1986; 11: 120-124.

6 Buchan H, Villard-Mackintosh L, Vessey MP, Yeates D, McPherson K. Epidemiology of pelvic inflammatory disease in parous women with special reference to intrauterine device use. Br J Obstet Gynaecol 1990; 97: 783-788.

7 Ross RK, Pike MC, Vessey MP, Bull D, Yeates D, Casagrande JT. Risk factors for uterine fibroids: reduced risk associated with oral contraceptives. BMJ 1986; 293: 359-362

8 Vessey MP, Villard-Mackintosh L, Painter R. Epidemiology of endometriosis in women attending family planning clinics. BMJ 1993; 306: 182-184.

9 Vessey M, Painter R, Mant J. Oral contraception and other factors in relation to hospital referral for menstrual problems without known underlying cause: findings in a large cohort study. Br J Fam Plann 1997; 22: 166-169.

10 Mant J, Painter R, Vessey M. Epidemiology of genital prolapse: observations from the Oxford-Family Planning Association study. Br J Obstet Gynaecol 1997; 104: 579-585.

11 Vessey M, Painter R, Yeates D. Mortality in relation to oral contraceptive use and cigarette smoking. Lancet 2003; 362: 185-191.

12 Breslow NE, Day NE. Statistical Methods in Cancer Research. Vol. 2: The Design and Analysis of Cohort Studies (IARC Scientific Publications No. 82). Lyon, France: International Agency for Cancer Research, 1987.

13 Vessey MP. 30th anniversary of the Oxford-FPA contraceptive study. Trends in Urology, Gynaecology and Sexual Health 1998; 3: 26-33.

14 Rose PG. Endometrial carcinoma. N Engl J Med 1996; 335: 640-649.

15 D'Souza RE, Guillebaud J. Risks and benefits of oral contraceptive pills. Best Pract Res Clin Obstet Gynaecol 2002; 16: 133-154.

16 Burkman R, Schlesselman JJ, Zieman M. Safety concerns and health benefits associated with oral contraception. Am J Obstet Gynecol 2004; 190: S5-S22.

17 The ESHRE Capri Workshop Group. Noncontraceptive health benefits of combined oral contraception. Hum Reprod Update 2005; 11: 513-525.

18 Haukkamaa M, Stranden P, Jousimies-Somer H, Siitonen A. Bacterial flora of the cervix in women using different methods of contraception. Am J Obstet Gynecol 1986; 154: 520-524.
19 Paavonen J, Critchlow CW, DeRouen T, Stevens CE, Kiviat N, Brunham RC, et al. Etiology of cervical inflammation. $A m ~ J$ Obstet Gynecol 1986; 154: 556-564.

20 Critchlow CW, Wolner-Hansen P, Eschenbach DA, Kiviat NB, Koutsky LA, Stevens CE, et al. Determinants of cervical ectopia and of cervicitis: age, oral contraception, specific cervical infection, smoking and douching. Am J Obstet Gynecol 1995; 173: 534-543.

21 Keshavarz H, Duffy SW, Sadeghi-Hassanabadi A, Zolghadr Z, Oboodi B. Risk factors for and relationship between bacterial vaginosis and cervicitis in a high risk population for cervicitis in Southern Iran. Eur J Epidemiol 2001; 17: 89-95.

22 Goldacre MJ, Loudon N, Watt B, Grant G, Loudon JDO, McPherson $\mathrm{K}$, et al. Epidemiology and clinical significance of cervical erosion in women attending a family planning clinic. BMJ 1978; 1: 748-750.

23 Harrison RH, Costin M, Meder JB, Bownds LM, Sim DA, Lewis $\mathrm{M}$, et al. Cervical Chlamydia trachomatis infection in university women: relationship to history, contraception, ectopy and cervicitis. Am J Obstet Gynecol 1985; 153: 244-251.

24 Ozbay K, Yardim T. The relation between cervical lesions and contraception method, smoking, parity, age and HRT. Jinekoloji ve Obstetrik Dergisi 2005; 19: 166-170.

25 Diddle AW, Gardner WH, Williamson PJ, O'Connor KA. Oral contraceptive medications and vulvovaginal candidiasis. Obstet Gynecol 1969; 34: 373-377.

26 Jensen HK, Hansen PA, Blom J. Incidence of Candida albicans in women using oral contraceptives. Acta Obstet Gynecol Scand 1970; 49: 293-296.

27 Davidson F, Oates JK. The pill does not cause "thrush". Br J Obstet Gynecol 1985; 92: 1265-1266.

28 Barbone F, Austin H, Louv WC, Alexander WJ. A follow-up study of contraception, sexual activity, and rates of trichomoniasis, candidiasis, and bacterial vaginosis. Am J Obstet Gynecol 1990; 163: 510-514.

29 Watt B, Goldacre MJ, Loudon N, Annat DJ, Harris RI, Vessey MP. Prevalence of bacteria in the vagina of normal young women. Br J Obstet Gynecol 1981; 88: 588-595.

30 Eschenbach DA, Patton DL, Meier A, Thwin SS, Aura J, Stapleton $A$, et al. Effects of oral contraceptive pill use on vaginal flora and vaginal epithelium. Contraception 2000; 62: 107-112.

31 Ocak S, Cetin M, Hakverdi S, Dolapcioglu K, Gungoren A, Hakverdi AU. Effects of intrauterine device and oral contraceptive on vaginal flora and epithelium. Saudi Med $J$ 2007; 28: 727-731.

32 Shraf-Ganjoei T. Risk factors for bacterial vaginosis in women attending a hospital in Kerman, Islamic Republic of Iran. Eastern Mediterr Health J 2005; 11: 410-415.

33 Smart S, Singal A, Mindel A. Social and sexual risk factors for bacterial vaginosis. Sex Transm Infect 2004; 80: 58-62.

\begin{tabular}{|c|c|}
\hline & $\begin{array}{l}\text { Faculty of Sexual and } \\
\text { Reproductive Healthcare } \\
\text { Clinical Effectiveness Unit }\end{array}$ \\
\hline & $\begin{array}{l}\text { A unit funded by the FSRH and supported } \\
\text { by NHS Greater Glasgow \& Clyde to } \\
\text { provide guidance on evidence-based } \\
\text { practice }\end{array}$ \\
\hline \multicolumn{2}{|c|}{ New Product Review (March 2009) } \\
\hline Cor & $\begin{array}{l}\text { lbined Vaginal Ring } \\
\text { (NuvaRing }^{\circledR} \text { ) }\end{array}$ \\
\hline $\begin{array}{l}\text { The Clinica } \\
\text { review of N } \\
\text { now license } \\
\text { freely avail } \\
\text { website - } \\
\text { (www.fsrh.o } \\
\text { \&SubSectio }\end{array}$ & $\begin{array}{l}\text { Effectiveness Unit has produced a } \\
\text { vaRing }{ }^{\circledR} \text {, the combined vaginal ring } \\
\text { for use in the UK. The document is } \\
\text { le for download from the FSRH } \\
\text { ee New Product Reviews section } \\
\text { /Default2.asp?Section=Publications } \\
=\text { ClinicalGuidance2). }\end{array}$ \\
\hline
\end{tabular}

